\title{
Fate, morals and rational calculations: Freezing eggs for non-medical reasons in Turkey
}

\author{
Azer Kılıç ${ }^{\mathrm{a}, *}$, İpek Göçmen ${ }^{\mathrm{b}}$

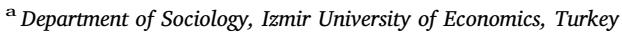 \\ ${ }^{\mathrm{b}}$ Max Planck Institute for the Study of Societies, Cologne, Germany
}

\section{A R T I C L E I N F O}

\section{Keywords:}

Turkey

Egg freezing

Social norms

Expectations

Rationality

Medicalization

Gender

\begin{abstract}
A B S T R A C T
This article aims to explore women's decisions to freeze their eggs for non-medical reasons in Turkey. It draws on semi-structured interviews conducted with twenty-one women who were either in the process of freezing their eggs, or had completed the process within the previous year. Being highly educated and holding prestigious occupations, on the one hand, and faced with traditional gender norms, on the other, these women are confronted with a challenging decision. When making such a decision to freeze their eggs, women act under the constraints defined by biomedical paradigms, the society they live in, and the future uncertainty of their lives. However, it becomes apparent that women are able to reconcile different kinds of rationalities and concerns in their decisions to freeze eggs. They engage in rational calculations to find a solution to their reproductive concerns; they turn to their own belief systems when dealing with future uncertainty; and they negotiate social norms concerning virginity, while trying to conform to traditional reproductive roles.
\end{abstract}

\section{Introduction}

The technology of oocyte cryopreservation, or, in lay terms, egg freezing, is one of the most recent phases in the medicalization of reproduction. This technology "anticipates" future infertility (Martin, 2010) as a result of women, due to their changing status in modern societies, increasingly delaying marriage and childbearing. Scientific methods can help forecast and plan for such future scenarios, to a certain extent, by examining the changes in women's ovaries, counting eggs, calculating the probability of pregnancy, and offering help measures such as egg freezing. Hence, in the news media, egg freezing is depicted as a "rational" strategy for women who want to pursue both career and maternal goals (Myers, 2014; Van de Wiel, 2014). However, women do not usually have only rational-utilitarian concerns, nor can the future be interpreted solely in statistical terms. This article explores women's experiences of freezing eggs for non-medical reasons in Turkey: we analyze the processes of decision-making by focusing on the roles that rational calculation, personal beliefs and social norms play in women's decisions and experiences of egg freezing.

The medicalization of reproduction can be considered to be a part of the broader process of rationalization that underpins modernity in Weberian terms (cf. Conrad, 1992: 213-214). One important dimension of this process as highlighted by sociologists-from Bourdieu (1979) to Beckert (2016) —is the future orientation of individuals. Scientific progress, secularization and capitalist development have enabled the "opening up of the future for rational calculation and planning" (Beckert, 2016), instead of relying on a religious notion of predestination and divine intervention. Such rationalization is underpinned by the means-ends type of social action (Kalberg, 1980). The process of modernization, however, has not unfolded in the form of a complete shift from traditional to modern practices; rather, they coexist. Social norms and beliefs continue to play a role in the rationalization process and are sometimes redefined.

The case of women freezing eggs for non-medical reasons in Turkey offers an interesting opportunity to consider the contemporary manifestations of rationalization in the areas of reproduction and future orientation. Being highly educated and holding prestigious occupations, on the one hand, and faced with traditional gender norms, on the other, these women are faced with an uneasy decision. When deciding to freeze their eggs, women act under the constraints defined by biomedical paradigms concerning reproductive aging, the society they live in, and future uncertainty concerning potential partners and eventual pregnancy. Still, we see that women can reconcile different rationalities and concerns in their decisions to freeze eggs. They engage in what we call rational calculations (the means-ends type of reasoning) in their efforts to find a solution to their reproductive concerns; they turn to belief-based expectations in dealing with future uncertainty; and they negotiate social norms concerning virginity, while trying to conform to

\footnotetext{
* Corresponding author. Izmir University of Economics, 35330 Balcova/Izmir, Turkey.

E-mail addresses: azerkilic@gmail.com, azer.k@ieu.edu.tr (A. Kılıç).
} 
traditional reproductive roles.

First, we shall review the literature on egg freezing with a focus on the medicalization of reproduction and its implications for women's choices. In the next section, we shall explain our methodological approach. Third, we shall provide some background information to situate the case within the Turkish context. In the fourth part, we shall provide the empirical analysis in three sub-sections: (a) how women engage in rational calculations when they consider egg freezing, (b) how they turn to beliefs in fate and God's will to deal with future uncertainty, especially once they start the procedure, and (c) how they negotiate social norms concerning reproductive roles and chastity throughout the process. After providing a discussion of the findings, we conclude the paper with an overview.

\section{Conceptual framework}

In this section, first of all we shall provide an overview of the literature on assisted reproductive technologies (ARTs) with regard to the medicalization of reproduction and women's choices. Second, we shall elaborate on the limitations of bioethical and rational choice approaches in order to situate women's decisions within the social and historical context.

\subsection{The medical rationalization of reproduction}

Providing a history of conception in The Baby Business, Debora Spar (2006) tells how the experience of (in)fertility used to be framed in terms of mysterious blessings, curses and superstitious fears in the premodern era. The idea of a woman's responsibility for her own "fate," such as that of infertility, would be supported with references to acts of God, among others. In the modern era, however, the notion of infertility has changed from a matter of fate to a physical condition treatable by scientific remedies, thanks to developments in medicine, such as an improved understanding of the biology of reproduction, the discovery of hormones and, more recently, the invention of in vitro fertilization (IVF). This has meant not only the advance of knowledge, but also "the advance of medicine into both the bedroom and the female body" (Spar, 2006: 11).

Medicalization has been a long debated topic in sociology and can be approached from a variety of perspectives. A pioneer in the literature, Zola (1972: 487) argued that "medicine [was] becoming a major institution of social control, nudging aside, if not incorporating, the more traditional institutions of religion and law." The medicalization of social problems was also assumed to lead to their exemption from religious inspection and, hence, from moral consequences. As a result, the issue of personal responsibility was redefined, in that it became more about what a person does about her medical problem, rather than about having a medical problem (Zola, 1972: 489-491). Discussing how earlier sociologists emphasized secularization as an important factor behind medicalization, Conrad (1992: 213) also observed that "many conditions have become transformed from sin to crime to sickness. In Weberian terms, this is of a piece with the rationalization of society." $\mathrm{He}$, however, noted that the relationship between medicine and religion is more complex (Conrad, 1992: 214). We will return to this topic in the next section.

The medicalization of reproduction, in particular, has also been a significant topic of debate for scholars, including feminist ones. Thompson (2005) divides the history of feminist literature on reproductive technologies into two periods: the first period takes place roughly during the 1980s when writers were generally critical of new assisted reproductive technologies, and the second one occurs roughly during the 1990s, when scholars were still concerned about their use but generally used a more ambivalent tone regarding them. Starting from the 1980s, the medicalization of reproduction was criticized by feminist scholars due to it being perceived as a patriarchal intervention into women's bodies (see, for instance, Oakley, 1984; O'Brien, 1981) and subjecting women to surveillance (Terry, 1989). There were also concerns about the legal and social regulation of these technologies (Corea, 1985; Stanworth, 1987). Feminist studies in the post-1990s, instead of being totally critical of reproductive technologies, paid more attention to how women experience infertility and such technologies (Becker, 2000; Franklin, 1997). Accordingly, Ginsburg and Rapp (1991: 330) underlined that "no aspect of women's reproduction is a universal or unified experience, nor can such phenomena be understood apart from the larger social context that frames them."

As a recent invention, the technology of egg freezing is a part of ARTs and rests on similar medical practices; yet, there are also some novelties about it. As Martin (2010) states, egg freezing is about an "anticipated infertility:" women seeking this treatment are not infertile in that moment, but they are diagnosed and treated for a future situation. To a certain extent, scientific methods can help with forecasting and planning for this future situation. As Waldby states, medical tests conducted in the clinical setting, such as ovarian reserve tests, "give patient and clinician a metric for future fertility and... introduce a degree of calculative rationality" (Waldby, 2015a: 478). These tests examine the qualitative and quantitative changes in the ovaries, warn against the "risks" of reproductive aging, such as (premature) menopause, and help calculate the probability of a woman getting pregnant using her own eggs through IVF. Egg freezing, hence, has appeared as a medical precaution against the situation of future age-induced infertility.

The medical rationalization of reproduction is accompanied with rational-choice approaches of social action in the news media (Myers, 2014; Van de Wiel, 2014), as well as in the newly developing literature on egg freezing. The procedure is often depicted in the literature as a "rational" strategy for "wise proactive women who take control of their fertility" (Linkeviciute et al., 2015: 1216). Some scholars, as well as the women studied by these scholars, frame egg freezing as an "insurance" mechanism or a "backup plan" against the "risks" of reproductive aging (Hodes-Wertz et al., 2013; Linkeviciute et al., 2015; Waldby, 2015b). Accordingly, several potential benefits are listed, such as extending the fertility period and so increasing time for education, investing in one's career, and forming a relationship, as well as increasing personal autonomy (Harwood, 2009; Mertes and Pennings, 2012; Savulescu and Goold, 2008; Waldby, 2015a).

Factors, or "costs," such as the health risks of egg freezing (e.g., concerning the use of hormones and egg retrieval surgery) and the high price of the procedure, as well as varying success rates for an eventual pregnancy, are also considered (Mertes and Pennings, 2012; Stoop et al., 2014; Lewis et al., 2016). Against this background, underlining the significance of "informed choice," scholars warn against selling "false hopes" and commercial exploitation (Harwood, 2009; Martinelli et al., 2015; Robertson, 2014). For instance, Mertes and Pennings (2012) argue that a lottery ticket would be a better analogy than an insurance policy for women freezing their eggs during the late thirties considering the lower success rate for older women.

Debates about the benefits and costs of egg-freezing technology for women (especially for working women) can be thought about in terms of neoliberal feminism, which requires women to adapt themselves to the idea of "human capital" by "investing" in themselves (Fraser, 2009; Repo, 2016; Rottenberg, 2017). Such an approach also implies the extension of market values and of an economic rationality of costs and benefits into new areas of life, as well as the future, as we shall elaborate on further below. Drawing on bioethics, concerns about costs also suggest the significance of rational expectations in decisionmaking; in other words, the use of probabilistic assessments and meansends calculations which are based on available information. However, decision-making, as well as expectations, does not happen in a vacuum. We need to consider the social context within which subjects are embedded and by which they are constrained (Carrol and Waldby, 2012; Murtagh and Hepworth, 2003). 


\subsection{The role of social norms and beliefs}

The rationality of egg-freezing behavior and women's decisions are more complicated than probabilistic assessments and calculations of costs and benefits. Social norms and beliefs, as well as institutional settings, also matter. Unlike the voluntaristic idea of careerist women controlling their fertility, egg freezing can also be seen as an outcome of social circumstances. This technology has been developed in a world characterized by increased female labor force participation, changing family structures, and economic liberalization (Esping-Andersen, 2015; Streeck, 2009). The increased flexibility of labor markets and the insufficiency of welfare state institutions concerning child and elderly care, among others, contribute to the postponement of motherhood and encourage women's decision to freeze eggs, as we show elsewhere (Göçmen and Kılıç, 2017; see also Cattapan et al., 2014).

The decision to freeze eggs can also be interpreted as "a refusal of more pragmatic, efficient reproductive options" (Waldby, 2015a: 478), such as egg donation and adoption, due to the prioritization of genetic continuity. Such prioritization might be related to prevailing social norms and beliefs. Decisions concerning motherhood and childbearing can hardly be understood without considering their meaning, infused with norms on gender and family, and their associated status in society. We will return to this topic in relation to the Turkish context.

Religion can also be an important factor for decisions concerning the use of ARTs. While medicalization may sometimes lead to the removal of an issue from religious inspection and, hence, from moral responsibility (Zola, 1972), at other times it may be faced with religious opposition. In Spar's (2006) words, the interference of science into "nature's intimate processes" can cause moral objections that the separation of sex and reproduction challenges the "religious sanctity of the creation of life" (see also Schenker, 2005). Hence, for instance, we can see that devout Catholic women shy away from IVF (Czarnecki, 2015). In a similar vein, the development of egg-freezing technology in Italy is linked to religious objections to, and legal restrictions on, embryo freezing and egg donation (Martin, 2010). Personal explanations for (in)fertility may also still include references to God's will (Conrad, 1992; Spar, 2006; Göknar, 2015).

Our study shows that egg freezing may cause further moral dilemmas for women: the transvaginal method of egg retrieval can lead to concerns for some women about the preservation of the hymen as an indicator of chastity. However, moral norms can be redefined through social processes. In the field of ARTs, one can first expect medicalization to exert an influence on the notion of moral responsibility (Conrad, 1992; Zola, 1972). One can also expect the commercialization of medical services and the use of marketing strategies, as well as consumer demands for medical services, to play a role in changing norms (cf. Conrad, 2008). The potential influence of medical markets is also consistent with the history of capitalist development. As seen in Zelizer's (1978) account of social resistance to life insurance in the United States in the nineteenth century, moral values can be redefined vis-à-vis practical needs and market solutions. The separation of sex and reproduction underlying the ARTs seems helpful in the case at hand: virgin women can take reproductive measures without having sex and redefine virginity in behavioral rather than biological terms. What initially seems to be in conflict with moral values, then, may acquire a normative aspect: the idea of egg freezing as a responsible act on the part of women toward their future partners.

Furthermore, the concern about selling false hope with an underlying support for rational expectations excludes the role of belief-based expectations in decisions concerning the future. In Imagined Futures, Beckert (2016) develops the notion of "fictional expectations" in contrast to the use of the notion of rational expectations in economic theory. While the notion of rational expectations assumes that individuals expect future outcomes on the basis of available information, the notion of fictional expectations underlines "imaginaries" vis-à-vis future contingency, hence, bringing social norms, emotions and beliefs into the picture. In this way, as shown below in the empirical analysis, an optimistic idea of predestination contributes to belief-based expectations, which are employed by women in order to reconcile themselves with uncertainty about future partners and pregnancy.

Overall, social norms and beliefs, as well as calculations of cost and benefit, are likely to play important roles in the processes of decisionmaking regarding freezing eggs for non-medical reasons.

\section{Methods}

In the second half of 2016, we conducted interviews with twentyone women who were either in the process of freezing their eggs, or had completed the process within the previous year. We recruited eighteen respondents through the assistance of a private fertility clinic in Istanbul, and three respondents through our personal contacts in the same city.

The median age of the sample was forty years and all were Turkish citizens. Twenty were employed, two of whom were working in the United States at the time but travelled to Turkey for egg freezing, and one respondent was unemployed. The occupations represented in the sample included lawyers, medical doctors, nurses, psychologists, academics, engineers and high-level managers. One respondent was a highschool graduate, while the remainder had university degrees, and about one third had postgraduate degrees. All of the respondents were unmarried at the time of the survey. Three were divorced and eighteen had never been married. Five were currently in a relationship, whereas the rest were single. Two respondents declared that they had never been in a romantic relationship, whereas six communicated that they had never had an experience of sexual intercourse.

The study has been approved by the Ethics Committee for Social Sciences of the Koç University. The authors gave respondents informed consent forms before the interviews.

The qualitative method of semi-structured interviewing was chosen as the data collection strategy. This method enabled us to collect data in a theoretically informed but relatively flexible way, as our aim was to explore women's experiences. Respondents were asked questions on how they had learned about the procedure, how they came to make the decision to freeze their eggs, how they felt both in psychological and physiological terms regarding the process, whether they had a problem paying for the procedure, and their expectations about the consequences of having their eggs frozen for possible future relationships. They were also asked questions about their past experiences and decisions concerning family responsibilities, romantic relationships, marriage and childbearing, as well as education and work.

Interviews were transcribed verbatim and names were replaced by pseudonyms. The analysis followed Boyatsiz's approach of thematic coding, which basically means presenting researchers' interpretations of how they see the data (1998: 4). Software was not used for data analysis since the authors wished to remain as close as possible to the data by repeated readings of the transcriptions. Therefore, analyses of the interviews were done manually. After a detailed reading of the interview transcripts by both authors, they separately completed a first round of initial coding of all the transcripts. The authors did not start the coding process with predefined codes from the existing literature, but after an initial reading of the transcripts as well as the literature; hence, the codes that were employed were both theory-informed and data-driven. Following the first round of coding, the authors came together to compare and discuss the initial codes and the coded data to see if there were any discrepancies and to reach inter-coder agreement (Campbell et al., 2013). After reconciling through discussion any coding discrepancies, the authors together categorized the coded data that was most relevant to the study goals under the main themes (such as rational calculations, appeals to beliefs and negotiation of social norms) and the sub-themes (such as the consideration of different options, optimistic fatalism and chastity).

The main limitation of this study is its biased sample. As mentioned, 
eighteen respondents were recruited through the assistance of a private clinic; hence, the sample consists of women who had high earning potential and were educated to a high level. However, this sample of women also emphasizes the dilemmas discussed in the article. Further research is needed to explore the experiences of women who go through the procedure in public hospitals.

\section{The Turkish setting: the legal framework and social indicators}

Since 2014, it has been legal to freeze eggs in Turkey in situations such as a decline in ovarian reserves or a family history of premature menopause; formerly, it was only allowed for disease-related reasons, such as for patients who would undergo cancer treatment or operations that may threaten reproductive functions. The use of frozen eggs for IVF is only allowed for married heterosexual couples. Prices vary according to the fertility clinic, and there is partial public insurance coverage at the limited number of public hospitals where the procedure is available. The private fertility clinic, where we conducted most of the interviews, charges about 2000 dollars per cycle (including clinic visits and egg retrieval), while hormone medications cost about 500 dollars per cycle and storage fees about 200 dollars per annum.

As the regulations imply, prevalent social norms underline marriage as a requirement for childbearing, deeming children born out of wedlock as illegitimate (Çarkoğlu and Kalaycıŏlu, 2012). Marriage and motherhood are, on the other hand, strongly enforced gender norms in Turkish society, where childlessness can be a source of stigmatization (Göknar, 2015). The male-breadwinner family model prevails as the ideal form, while the employment of women who have small children is rare. This family model is backed by the welfare system, as we show elsewhere (Kılıç, 2008).

Statistics also suggest delayed marriage and motherhood to be uncommon phenomena: the median age for first marriage by women was 21 and the median age for the birth of a first child, by women between the ages of 25 and 49, was 22.9 in 2013 (HÜNEE, 2014). On the other hand, the rate of childless women aged between 35 and 49 was 6.8 per cent in 2013 (HÜNEE, 2014). A recent comparative study shows that the propensity to lifelong singlehood, especially among highly educated women, is greater in societies where traditional norms prevail concerning gender roles; hence, demonstrating a lack of adaptation to women's changing roles (Bellani et al., 2017). The uncommon characteristics of the women in our sample concerning marital status and childbearing can be interpreted in these terms as well.

While marriage during the early twenties is a prevalent norm, premarital sexuality is still a taboo. According to the findings of the World Value Survey, sex before marriage was never justifiable for 76.7 percent of the respondents in Turkey (WVS, 2014). This is an extremely high figure compared to Western countries (e.g., $8 \%$ for Germany and $13.5 \%$ for the US). Virginity before marriage also continues to be an important norm for many highly educated women (Ozyegin, 2015; Scalco, 2016), as manifested in our sample.

Education statistics also demonstrate the unusual social placement of our sample. Tertiary education attainment has been increasing in the last decade, but it is still low: in 2014, it was 13.2 percent for women aged twenty-five and above. Graduate level education is even rarer: in 2015 the ratios were 1.4 for master's level and 0.2 for doctoral level attainment among women (World Bank, 2017). On the other hand, as mentioned above, all the women, except one, in our sample were university graduates, and one third had postgraduate degrees.

Linked to education, female labor force participation is also low in Turkey. The rate was 35 percent across the country in 2015. Female employment in the urban areas is concentrated in the services sector, characterized by low-paying and low-skilled jobs. The rates of employed women with managerial and professional occupations were, respectively, 2.2 and 14.3 percent in 2015 (TURKSTAT, 2016). These are important indicators to understand the privileged status of the women interviewed for this study, as they occupy either managerial or, more commonly, professional positions. The resulting picture is also consistent with the typical profile of egg-freezing women as depicted in the Western media (Myers, 2014; Van de Wiel, 2014).

\section{To freeze or not to freeze: how do women decide?}

In this section, first, we analyze how women evaluate reproductive aging, and decide to freeze eggs and increase their objective chances of a future pregnancy, by engaging in rational calculations. Such calculative reasoning takes place particularly in the early phases of decisionmaking. Second, we depict how women take refuge in their religious beliefs in their efforts to give meaning to their experiences and to deal with future uncertainty. Religious reasoning mostly influences the process of decision-making after women start freezing their eggs. For some women, this mode of reasoning helps with the decision whether to do multiple cycles or not. And, for many, it helps with anxieties about the future, especially once they have some eggs frozen. Third, we show how, during this process, women negotiate and selectively redefine social norms concerning reproductive roles and virginity. This mode of social reasoning is implicated throughout the process of decisionmaking; it influences women's decisions to freeze their eggs in the first place and their decisions about which procedure to use, and how to negotiate possible surgical damage to the hymen.

\subsection{Engaging in rational calculations}

Most women in our sample encountered the idea of egg freezing through their gynecologists. Considering a woman's age, or in some cases complaints about irregular menstruation, gynecologists discuss the risk of menopause, point at diminishing ovarian reserves supported by clinical tests, and suggest egg freezing as a precaution. Women follow this up with internet research on reproductive aging, egg freezing and IVF treatments. Thus, women are provided with new information which facilitates their engagement in rational calculations and consideration of future scenarios. For instance, Defne, who is a doctoral researcher and faced with the risk of premature menopause at the age of 29 , tells us that she considered all the options once she learned about her medical situation:

First, I thought about having a child with one of my ex-boyfriends, because my chance of becoming pregnant is higher now, and I thought I'd get divorced if things didn't work out. Then I thought that this was nonsense. I also thought about adoption, in case this [egg freezing] doesn't work.

This comment is linked to one of the most frequently mentioned concerns: not to rush into a "wrong" relationship and pregnancy because of the sudden fear of infertility and the pressures of the "biological clock." Deniz, 42, a clinical psychologist, recounts a similar story involving some hard thinking before making her decision to undergo the procedure:

I thought about what I wanted now. I said: 'I want to have a child.' But I don't have a serious relationship right now and I don't want to miss the train. Yet at the same time, I don't want to rush into finding someone, getting married and having a child either... I didn't want to make a wrong decision.

Having attained a high level of education, women also usually draw on their professional perspectives in the process of decision-making. Merve, who is a 38-year-old clinical psychologist, says that it makes her feel better to have such an opportunity: "I will not think, 'it's too late, damn it', when I'm in that stage of life when I cannot have a child physiologically." Reminding us about her profession (and implying selftreatment), Merve argues that such psychological relief will also make it easier for her to date new people; otherwise, she argues, "things may get blocked due to anxiety", pointing at potential behavioral inhibition.

Another professional perspective toward decision-making is that of 
the engineer looking for an "optimum solution." Ela, a 43-year-old engineer, describes her approach:

I am trying to increase the probability [of childbearing]. I am a rational person, an engineer, therefore I can deal with probabilities... When deciding, you should consider both cause and effect when projecting the future. Engineering is about finding an optimum solution under given constraints.

Research suggests that the optimum number of eggs for maximizing the chance of live birth through IVF is fifteen (Baldwin et al., 2015). Ela says that the success rate for her age is between 5 and 10 percent for ten eggs. Hence, she decided to undergo three cycles to obtain a good number of eggs for freezing. Her gynecologist suggested collecting twenty eggs in total, but she has decided to freeze thirty eggs so that she can "have a higher probability of eventually having at least three healthy eggs fertilized." When asked about the high financial cost of multiple cycles, Ela says, like many others, that she does not mind the cost. She argues that it is not high considering the probability of having a child in the future, noting that if she does have a child, then she will need to spend much more anyway.

Concerning the cost, Ayşe, 41, a project manager, also argues that money was not an issue for her. The desire of "not having any regrets in the future" is an often mentioned concern. Ayşe says that she would prefer not to feel any regrets and spend the money, as to do otherwise would make her "neither richer nor poorer." However, Ayşe also uses an economic analogy for her frozen eggs: "I am depositing money in the bank. I don't know if I will use it or not, but it makes me feel better." We heard similar expressions for egg freezing from other respondents, such as "savings account," "insurance plan" and "investment in one's self." These economic analogies can be considered in relation to the neoliberal era: they suggest the extension of an economic rationality and of market values into new areas of life, including the future. In the case at hand, we see that women can also apply the idea of human capital to matters of reproduction and, hence, to associated issues, such as marriage and status in society (cf. Repo, 2016; Rottenberg, 2017).

Sezen, 41, an academic working at a college in the United States, takes risk calculation to a higher level: she has decided to undergo the treatment both in Turkey and the US. While it is much cheaper in the former country, she aims to carry out the procedure in the US as well, considering both the legal framework and the societal context-prevailing norms about marriage and childbearing—for using the frozen eggs for IVF through sperm donation: "if I get married, I can use [the eggs] in Turkey. But there is a chance that I won't, then I think that I'd better have a few eggs in the US as well. So, I feel like I have to distribute the risk."

In a similar vein, Ekin, 37, an attorney, in a highly rational manner explains her decision to get eggs frozen:

... there is a risk here, there might be a negative situation in the future, and I now have the chance to prevent that situation; so, I've made use of that chance. Hence, I'm seeing it in technical terms. I haven't developed an emotional bond with my eggs.

Ekin's comment suggests a resistance to the approaches that would moralize the use of reproductive technologies and advocate restricting the use and storage of human biological materials for ethical and religious reasons.

We also see detailed calculations for the future use of frozen eggs. For instance, Yasemin, 40, an engineer, has set a timeframe of five years for the use of eggs she aims to get frozen. "If I can find someone within the next two or three years, it's fine; otherwise, those eggs will go into the dustbin," because she does not want to be an "old mother" for the good of both herself and of her child. Handan, 44, a physician, on the other hand, does not think of going through IVF at all: "I don't want a pregnancy after this age. Pregnancy is not an easy thing. It can damage me [health-wise]." Handan thinks of using the eggs for surrogacy motherhood in the future, in case it becomes legal in Turkey. If surrogacy doesn't work, she adds, she might consider foster care.

Overall, when faced with the idea of reproductive aging, women engage in rational calculations concerning their current and future options; they consider legal and societal constraints regarding the use of reproductive technologies, compare costs and benefits, and decide accordingly. Women also adapt well to the technology of egg freezing in their efforts to preserve reproductive capacities, as they aim to increase their objective chances by increasing the number of eggs frozen. We also see that women draw not only on their knowledge of reproductive technologies, but also on their professional perspectives, such as the engineer's aim to find an optimum solution based on probabilistic assessments, and the psychologist's self-treatment for potential behavioral inhibition due to anxiety. These are consistent with the rational-choice perspective seen in the literature and an expected outcome of medicalization; but there are also other aspects around the decision to freeze eggs, as we shall see below.

\subsection{Turning to beliefs}

The women in our sample are aware that their chances of having a child are not high, especially as some women have only had one egg frozen. They do, however, draw on their belief in fate and God's will to give meaning to their experiences and to cope with uncertainty. For instance, Yasemin acknowledges that her chances are low, arguing that it would be a "miracle" if she manages to have a child from her very limited number of frozen eggs. But she wants to believe in this miracle:

In medicine every single person is special; the result is different for every single person. So, no one knows what will happen. In my case, success can only come about through a miracle. Can we find any [egg] from those that remain? Will it be good enough to freeze and then will the frozen one be successful? So, it is troublesome, but I am very hopeful, I have faith in this, because everything has a reason, there must be a reason that I am faced with this issue now.

Ekin's remarks also touch on the role of contingency in future outcomes with an optimistic fatalism. She too argues that "there is a reason for everything that happens" and that "we do not get access to any information without a reason." She regularly visits a gynecologist every year; however, on her last visit she underwent some new tests, including the AMH test, because of an incident of unusual bleeding. She continues:

I've never had mid-term bleeding before, this was the first time. As a result of this, I had the test done and learned that there is a risk [of infertility], so I decided to get it [egg freezing] done to minimize the risk... Whether you have a child or not is actually a matter of destiny.

Some respondents perceive the process to be a spiritual one, suggesting divine intervention and referring to God's will. Çağla, 41, an academician, relates:

It was as if God was telling us we had to visit a doctor. Even the doctor said, 'I could not even collect one egg, so how can you already think about having a child?'... Sometimes when I lose hope, I think, I believe in God, if this [childbearing] were not [our] destiny, then why would our God put us through so much stress?... Sometimes I think that God is testing my faith. If it is our destiny, it will happen.

Similarly, referring to her religious beliefs, Sezen is quite aware that they also function as a coping mechanism: "I do whatever I can, and tell myself that if it's my fate, God will allow it to happen. I cannot deal with it otherwise. If I try to control it, I think I would lose my mind."

Another recurrent theme is the recounting of success stories of other women who became pregnant at an older age, which is usually seen as connected with the idea of fate. For instance, Ece, a 38-year-old engineer, shared with us the experience of one of her colleagues, who paid 
a regular visit to a gynecologist. The gynecologist informed her that she was about to enter premature menopause, that she had a cyst, and that it would be nearly impossible for her to have a child even through IVF. However, her colleague, devastated to hear such news, met a man a couple of months later and became pregnant. Ece enthusiastically commented:

Can you believe it? The girl is pregnant now. We are talking about a case in which the doctor said it is 99 percent impossible and the girl got pregnant on the first night!... These things are totally a matter of fate. Not mathematics. Not the AMH. Because the girl's AMH level was so low, she was about to enter the menopause. So if it is to happen, it happens!

Personal past achievements are also interpreted in such a way as to keep hopes high, by thinking of themselves as exceptional. This is usually either from a remark about a job that was hard to get, or a school-entrance exam that was extremely competitive. For example, Sezen says:

They tell me that it is hard for me to have a kid because they have to find an egg first. They are having difficulty in finding one. But I believe that if they can find one egg, it [childbearing] can happen. I also found my job with a chance of one in a thousand. That is how I have achieved everything in my life.

Because of a belief in fate, one respondent did not chose to undergo many cycles, unlike others who did so to increase the probability. Leyla, 41, a marketing agent, argued that "if it is to happen, it should be enough to have one cycle," despite the suggestion of her gynecologist to go for another cycle to increase her objective chances. Leyla says that she believes in "the magic of it" (işin büyüsü). We heard similar comments from some other respondents, such as "better to leave some things to nature," or their worries about "acting against spontaneity" by using reproductive technologies.

Interestingly, many women communicated that they did not care about the risks involved, and some women intentionally ignored them. Defining themselves as very cautious concerning other life issues, women claim that they just want to see the positive side and believe in the possibility of having a child. Defne says: "I have no idea about the risks of the medication. I was simply shocked and have not done any research. I would usually read up about things. But I currently am not reading anything... nor do I care... I just take the medicines."

Overall, women draw on their belief in fate and God's will when deciding about reproductive matters (cf. Göknar, 2015; Spar, 2006). These beliefs help give meaning to women's experiences of egg freezing and to deal with future uncertainty. The beliefs usually do not seem to conflict with egg-freezing technology. There are a few exceptions though: in several cases women were unable to produce more than one egg but they still insisted on egg freezing, and, in another case, a woman did not want to go for additional cycles, contrary to the suggestion of her gynecologist that it would increase her objective chances. Women also interpret their past achievements, as well as the success stories of other women, in relation to their ideas on fate and their exceptionality in order to keep their hopes high. Some even intentionally ignore risks or low success rates. This attitude conflicts with the bioethical approach: women deliberately embrace what is called "false hopes." Therefore, it might be better to think of them as belief-based expectations, since it is not simply a matter of a lack of access to information or of commercial exploitation.

\subsection{Negotiating social norms}

Many of the women in our sample explain their decisions to freeze eggs as the fulfillment of a responsibility to preserve their fertility (cf. Rottenberg, 2017). How this responsibility is defined changes, yet one common topic is an "imagined future" (Beckert, 2016) with a lover or a husband. Many women stated that having their eggs frozen would probably have a positive influence on their future relationships. Anticipating approval from a future partner, Merve has a similar view:

I think I will be appreciated. I think I will hear something like 'I am glad that you thought about this and have done this'... This is actually one of the reasons behind my decision. If we really want to have a child at some point, I do not want to say 'I heard about it, there was an opportunity, but I did not do it.'

Believing that egg freezing preserves fertility, women also experience a boost of self-esteem and self-worth. Sezen explains how:

Freezing eggs preserves my fertility and this increases my self-confidence. Previously, I felt like I was losing my self-confidence... [Egg freezing] gave me some hope... I think the man I will marry will thank me for doing this... I think the man who takes me is lucky. I have prepared everything for him. Sometimes men have to go through this in a marriage, and financially and emotionally share [the burden]. I will prepare everything and then present it to him.

Some women also explicitly shared their concerns about being rejected by men due to lost fertility. For instance, Defne recounts how it stresses her out thinking that a future lover who wants to have children may not accept her as she is, and may leave her instead. She adds: "maybe I can imagine a future without a child, but what if the guy cannot? If he is someone who wants children, then, this will probably influence his decision [to stay with me]... I am thinking about all this and it makes me so sad."

Similarly, by keeping her options to having a child open, Deniz believes she has increased her chances of having a future long-term relationship:

Let's imagine that someone wants to have a child. He might wonder how this woman, at forty-two, could have a child, that it's better he end the relationship before it's too late, otherwise it would be harder, and it's better he leaves her before becoming too attached. But now, on the contrary, if we want to have a child, we will still have the option.

These concerns relate to the prevailing norms on gender roles and status within society. Ece explains the societal aspects in her own words: she believes that there is a status difference between single and married women. Married women are "a step higher" than single women; if they become a mother, then they are at an even higher level. If she were an employer, she argues, she "would not hire a single, childless woman such as herself," since she would "not be efficient enough" due to "unhappiness" caused by "social exclusion." Considering the prevailing gender norms and women's perceptions of the existing social order, we can argue that women try to preserve their value in the dating market and ensure their higher status within society by freezing their eggs.

When women have to decide to preserve either their fertility or their virginity, they opt for the former. As mentioned above, premarital sex is still a taboo in Turkey and virginity is widely seen as essential for marriageability. Out of our sample, six respondents had never had sexual intercourse before, and had damaged their hymens due to the egg-retrieval operation. When Sezen learned that retrieval would be carried out through transvaginal ultrasound aspiration, she says she did not care. It is clear that she had started to redefine virginity as a matter of health, rather than of morality:

Virginity was an important thing for me. I was a virgin, but when I needed to make this choice, then I did not care. I told myself that this is my only opportunity and the person I will marry will understand... In the end, this is similar to an illness. You do whatever is necessary for your health... What value has virginity if you cannot have a child anymore?

In a similar vein, Çağla questions its significance and redefines it in behavioral rather than biological terms: "What is virginity? It is the 
presence of a hymen... [but] one has to think about the definition of virginity. In the end, I have had my hymen broken through an operation, [but] my virginity is still there." She says that she will still wait until marriage before she becomes sexually active.

Unlike the women who recounted that they had deliberately remained virgins for moral reasons, Ela argues that she is still a virgin because her ex-boyfriend of seven years did not want to accept the "responsibility" of engaging in pre-marital sex; that is, he would then feel obliged to get married. Currently not in a relationship, Ela argues that it is probably "better that [she] got rid of it [hymen], considering the difficulty it caused [for her] in the past," and adds that "a man similar [to her] in terms of age and status would not expect [her] to be a virgin at the age of forty-three."

Hence, our respondents seem to have had no decisional conflicts regarding virginity. We also should note that the market for reproductive services and health care is able to offer remedies in case of possible decisional conflicts. In some hospitals in Istanbul, egg retrieval is also offered via laparoscopy so that the hymen is not damaged. In the fertility clinic where we conducted our interviews, we were informed that they do not use this method "as it is not efficient; " however, they told us about the calls they receive from women concerning the method, and that overly concerned women opt for clinics which use laparoscopy. There are two other options, one of which is also available at our clinic: the provision of medical papers, upon request, certifying that the person's hymen was damaged as a result of an egg-retrieval operation. One respondent told us that she would get the paper "just in case." The other option available is hymen reconstruction. This is a socially stigmatized procedure and a couple of respondents mentioned it only as something they would not pursue, calling it "cheating."

Overall, we have seen that throughout the egg-freezing process, women negotiate social norms. On the one hand, they accept their reproductive role and aim to fulfill their responsibility by trying to preserve their fertility. By preserving their fertility, it seems as if women are also trying to preserve their marriageability and, thus, ensure a better place for themselves within society. On the other hand, women chose fertility over virginity, once a choice between the two becomes necessary. While legitimizing their decision by calling it a matter of health, they also redefine virginity in behavioral rather than biological terms. Hence, the separation of sex and reproduction that underlies the ARTs helps to reconcile morals with reproductive technologies (cf. Spar, 2006). The market for reproductive services and health care also offers remedies which aim to reconcile opposing forces. This is consistent with the history of the expansion of markets, as told by Zelizer (1978). What initially appears to be at odds with moral values may achieve a socially acceptable form, or even become a social norm-the idea that egg freezing is the responsible act of a woman toward her future partner.

\section{Discussion}

Women employ different modes of reasoning when they decide to freeze their eggs and contemplate how to deal with its potential consequences. These modes of reasoning-briefly, rational, religious and social—can be linked to the debates in the literature concerning the relationship between secularization, rationalization and medicalization, as well as the gendered nature of medicalization. In our study, the nature of the relationship between religion and medicalization appears to be contingent on the lived experiences of individual women. The women in our sample accept the medicalization of age-related decline in fertility and decide to receive medical intervention, rather than leaving things to "fate." We see that gynecologists play an important role here in introducing the idea of risk and orienting women towards ARTs and, hence, to the rational calculative mode (cf. Conrad, 1992). Thanks to their education and their professional backgrounds, these women are also used to making risk calculations and looking for optimum solutions (cf. Hodes-Wertz et al., 2013; Waldby, 2015a; Waldby, 2015b).

During the process of egg freezing, however, women take refuge in their religious beliefs, such as fate, to deal with the anxiety related either to the low numbers of eggs frozen or to future uncertainty about pregnancy. Religious reasoning takes place mostly during the process of dealing with daily shots of hormones, waiting to undergo egg retrieval surgery, and even waiting for the future use of frozen eggs; hence, the women are usually very emotional. These women, thereby, support their experiences of medicalization with their belief-based expectations (cf. Conrad, 1992; Göknar, 2015; Spar, 2006). Yet, in some cases there can also be a conflict between medicalization and religion: one woman in our sample rejected undergoing further cycles to increase her objective chances, contrary to the recommendations of her gynecologist. By doing so, she tried to keep medical intervention to a minimum and to allow more room for divine intervention. This case is an exception, however, and the conflict was not enough to prevent the use of ARTs altogether.

The mode of social reasoning in women's decision-making has different aspects. One aspect is again related to the secularization thesis. The medicalization of age-related decline in fertility removes virgin women from the moral responsibility of preserving the hymen as an indicator of chastity. The virgin women in our sample, who also tend to be the most religiously devout ones, make use of medicalization to justify this decision: either framing it as a matter of health rather than of morals, or starting to define virginity in behavioral terms. Hence, these women did not experience a severe conflict in their decision to undertake transvaginal surgery for egg retrieval. The market for reproductive services also provides remedies in case a woman may feel such a conflict-the provision of medical papers certifying the pretransvaginal surgery situation, and the option of using laparoscopy instead. Therefore, medicalization and marketization together can exert a significant influence on moral norms (cf. Conrad, 2008; Zelizer, 1978; Zola, 1972). As egg freezing is also framed as a responsibility toward their future partners, women themselves appear as active participants in selectively redefining gender and moral norms (cf. Cattapan et al., 2014).

As to other aspects of the mode of social reasoning, the women's decision to preserve their fertility is closely linked to the existing status order regarding marriage, reproductive roles and gender. This decision is, first of all, an acceptance of the role of motherhood and the prioritization of genetic continuity in having children (cf. Waldby, 2015a). Second, some women perceive fertility as a major criterion of marriageability and marriage as an important social norm, influencing one's place in the social hierarchy and even job opportunities. These social pressures are coupled with the stigmatization of female aging (Segal, 2013). Against this background, we can argue that the women, by freezing their eggs, are trying to preserve their self-worth as the menopause approaches, maintain their value in the dating market, and secure a better position in the status order. We contend that women employ egg freezing, not only for an imagined future of dating and childbearing, but also for their ongoing struggles regarding gender roles and aging. Almost all of the women we interviewed had told their families and close friends about their decision to freeze their eggs, and they talked about how their decisions were greatly supported. Therefore, the women might also be mobilizing egg freezing to gain approval within their social circles and/or to avoid social pressure to hurry up marriage and childbearing. Considering our earlier discussion on the literature on egg freezing, with its emphasis on costs and benefits, the study at hand also suggests some of the practical benefits of egg freezing for women without, however, challenging the underlying issue of a social hierarchy based on traditional gender norms.

\section{Conclusion}

This study examines how women decide to freeze their eggs for nonmedical reasons in Turkey. Our findings show that women use different 
modes of reasoning when choosing to freeze their eggs. Women draw on rational calculations in the initial phases of making such a decision, to increase their objective chances of pregnancy under the given circumstances. Therefore, they consider reproductive options, assess means and ends, and formulate optimum solutions. Many of these women take refuge in their religious beliefs once they are faced with new sources of anxiety, such as uncertainty about the future use of frozen eggs. Religious reasoning helps women to give meaning to their experiences and to have optimistic expectations. Most women also negotiate social norms throughout the process: on the one hand, they aim to conform to expected reproductive roles, preserve their fertility and marriageability, and ensure a better position for themselves in the social hierarchy, which puts a significant emphasis on marriage and motherhood. On the other hand, women selectively redefine moral norms: if the hymen, which should be preserved as an indicator of chastity, is to be damaged because of egg retrieval surgery, women medicalize the hymen and redefine virginity in behavioral terms. Some also frame egg freezing as a responsibility toward future partners.

The study, hence, makes two important contributions to the existing literature on egg freezing: firstly, its focus on a non-Western context and, secondly, on social norms and belief-based expectations, to explain women's decisions to freeze their eggs for non-medical reasons. The existing literature on egg freezing, although newly developing, offers important insights into the medical issues within a Western context. We see a special emphasis on bioethical and rational choice approaches in the literature. These approaches underline the rational calculations of costs and benefits, assessments of means and ends, and probabilistic expectations based on available information, while warning against selling false hopes. Hence, the studies focus on some significant factors for decisions concerning egg freezing. However, as our study within a non-Western context shows, social norms and religious beliefs, as well as rational calculations, are also significant factors regarding egg freezing, especially for non-medical reasons.

Considering the broader literature on medicalization, the study also provides further elaborations about the following interrelated dimensions of the use of ARTs: the nature of patients' expectations; interactions with religion; and gendered aspects.

First of all, the technology of egg freezing, by drawing on scientific methods to examine a woman's reproductive capacity and to calculate the probability of pregnancy through IVF, "opens up the future for rational calculation and planning" and enables "rational expectations" (Beckert, 2016). This medically rationalized approach to reproductive matters is backed by a neoliberal feminism, which propagates the idea of human capital and calls to women to manage risks and invest in themselves. Hence, a neoliberal logic influences decision-making concerning reproductive matters. However, we contend that belief-based expectations also play a significant role in decision-making and such expectations go beyond the notion of false hopes, since they are not simply a matter of imperfect information or commercial exploitation (cf. Beckert, 2016).

Second, while the literature notes that medicalization can sometimes face religious and moral objections, our study shows that religious beliefs are mostly used in a way to support the personal experiences of medicalization and that morals can be redefined. The women in our sample are usually able to reconcile egg freezing with religious reasoning. This appears to be thanks to a flexible interpretation of religious ideas, such as fate. Closely linked to religion, morals are also influenced in this process from medicalization and marketization. Hence, we think that the development of medical markets and the increase in consumer demands for medical services are likely to further complicate the influence of medicalization on society (cf. Conrad, 2008).

Third, the medicalization of age-related decline in fertility has diverse implications for gender. By freezing eggs, women can both accommodate and challenge traditional gender norms. In our study, it is traditional reproductive roles that the women aim to conform to and sexual morals that they attempt to redefine. While some women's adoption of the neoliberal notion of self-investment might seem worrisome to those critical of such ideas, the negotiation of moral symbols such as the hymen, in the case of virgin women, can be seen as an advance brought about by egg freezing technology, from a feminist perspective (cf. Cattapan et al., 2014). Further studies can explore these issues within the context of different countries.

\section{Acknowledgments}

We are grateful to the editor and three anonymous reviewers for their suggestions and comments on the paper. We thank MD Bülent Urman, MD Ayşen Boza, Zehra Özdinç, Büşra Kartal and Melek Güre Turan for their help with accessing respondents. We also thank İem Aral and Simla Serim for their help with the transcription of interviews. İpek Göçmen thanks the Bogazici University Social Policy Forum for its support. An earlier version of this paper was presented at the IMPRS Conference on the Social and Political Constitution of the Economy, Max Planck Institute for the Study of Societies, 27-28 July 2017.

\section{References}

Baldwin, K., Culley, L., Hudson, N., Mitchell, H., Lavery, S., 2015. Oocyte cryopreservation for social reasons: demographic profile and disposal intentions of UK users. Reprod. Biomed. Online 31, 239-245.

Becker, G., 2000. The Elusive Embryo: How Women and Men Approach New Reproductive Technologies. University of California Press, Berkeley.

Beckert, J., 2016. Imagined Futures: Fictional Expectations and Capitalist Dynamics. Cambridge MA. Harvard University Press.

Bellani, D., Esping-Andersen, G., Nedoluzhko, L., 2017. Never partnered: a multilevel analysis of lifelong singlehood. Demographic Research 37 4, 53-100.

Bourdieu, P., 1979. Algeria 1960. Cambridge University Press, Cambridge.

Boyatzis, R.E., 1998. Transforming Qualitative Information: Thematic Analysis and Code Development. Sage Publications, London.

Campbell, J.L., Quincy, C., Osserman, J., Pedersen, O.K., 2013. Coding in-depth semistructured interviews: problems of unitization and intercoder reliability and agreement. Socio. Meth. Res. 42, 294-320.

Carrol, K., Waldby, C., 2012. Informed consent and fresh egg donation for stem cell research: incorporating embodied knowledge into ethical decision-making. Bioethical Inquiry 9, 29-39.

Cattapan, A., Hammond, K., Haw, J., Tarasoff, L.A., 2014. Breaking the ice: young feminist scholars of reproductive politics reflect on egg freezing. Int. J.Feminist Approaches Bioeth 7, 236-247.

Conrad, P., 1992. Medicalization and social control. Annu. Rev. Sociol. 18, 209-232.

Conrad, P., 2008. The Medicalization of Society: on the Transformation of Human Conditions into Treatable Disorders. Johns Hopkins University Press, Baltimore.

Corea, G., 1985. The Mother Machine: Reproductive Technologies from Artificial Insemination to Artificial Wombs. Harper \& Row, New York.

Czarnecki, D., 2015. Moral women, immoral technologies: how devout women negotiate gender, religion, and assisted reproductive technologies. Gend. Soc. 29, 716-742.

Çarkoğlu, A., Kalaycıŏglu, E., 2012. Türkiye'de Aile, İş ve Toplumsal Cinsiyet. Istanbul Policy Center, Istanbul Family, Work and Gender in Turkey.

Esping-Andersen, G., 2015. The Incomplete Revolution: Adapting to Women's New Roles. Polity Press, Cambridge.

Franklin, S., 1997. Embodied Progress: a Cultural Account of Assisted Conception. Routledge, London.

Fraser, N., 2009. Feminism, capitalism and the cunning of history. N. Left Rev. 56, 97-117.

Ginsburg, F., Rapp, R., 1991. The politics of reproduction. Annu. Rev. Anthropol. 20, 311-343.

Göknar, M.D., 2015. Achieving Procreation: Childlessness and IVF in Turkey. Berghahn Books, New York and Oxford.

Göçmen, İ., Kılıç, A., 2017. Egg freezing experiences of women in Turkey: from the social context to the narratives of reproductive ageing and empowerment. Eur. J. Wom. Stud. http://dx.doi.org/10.1177/1350506817742929. Advance online publication.

Harwood, K., 2009. Egg freezing: a breakthrough for reproductive autonomy? Bioethics 23, 39-46.

Hodes-Wertz, B., Druckenmiller, S., Smith, M.D., 2013. What do reproductive-age women who undergo oocyte cryopreservation think about the process as a means to preserve fertility? Fertil. Steril. 100, 1343-1349.

HÜNEE, 2014. 2013 Türkiye Nüfus Ve Sağlık Araştırması. Hacettepe University Population Studies Institute, Ankara Research on Population and Health in Turkey.

Kalberg, S., 1980. Max Weber's types of rationality: cornerstones for the analysis of rationalization processes in history. Am. J. Sociol. 85, 1145-1179.

Kılıç, A., 2008. The gender dimension of social policy reform in Turkey: towards equal citizenship? Soc Pol. Adm 42 5, 487-503.

Lewis, E., Missmer, S., Farland, L., Ginsburg, E., 2016. Public support in the United States for elective oocyte cryopreservation. Fertil. Steril 106 5, 1183-1189.

Linkeviciute, A., Peccatori, F.A., Sanchini, V., Boniolo, G., 2015. Oocyte cryopreservation 
beyond cancer: tools for ethical reflection. J. Assist. Reprod. Genet. 32, 1211-1220. Martin, L.J., 2010. Egg freezing, genetic preservation and risk. Gend. Soc. 24, 526-545. Martinelli, L., Busatta, L., Galvagni, L., Piciocchi, C., 2015. Social egg freezing: a reproductive chance or smoke and mirrors? Croat. Sports Med. J. 56, 387-391.

Mertes, H., Pennings, G., 2012. Elective oocyte cryopreservation: who should pay? Hum. Reprod. 27, 9-13.

Murtagh, M.J., Hepworth, J., 2003. Feminist ethics and menopause: autonomy and decision-making in primary medical care. Soc. Sci. Med. 56, 1643-1652.

Myers, C.E.C., 2014. Colonizing the (reproductive) future: the discursive construction of ARTS as technologies of self. Frontiers 35 1, 73-106.

Oakley, A., 1984. The Captured Womb: a History of the Medical Care of Pregnant Women. Blackwell, Oxford.

Ozyegin, G., 2015. New Desires, New Selves: Sex, Love, and Piety Among Turkish Youth. New York University Press, New York.

O'Brien, M., 1981. The Politics of Reproduction. Routledge and Kegan Paul, London.

Repo, J., 2016. Gender equality as biopolitical governmentality in a neoliberal European Union. Social Politics 23 (2), 307-328.

Robertson, J.A., 2014. Fresh, frozen, and fabricated eggs. Am. J. Bioeth. 13, 5-7.

Rottenberg, C., 2017. Neoliberal feminism and the future of human capital. Signs 42 (4), 329-348.

Savulescu, J., Goold, I., 2008. Freezing eggs for lifestyle reasons. Am. J. Bioeth. 6, 32-35. Scalco, P.D., 2016. The politics of chastity: marriageability and reproductive rights in Turkey. Soc. Anthropol. 24 (3), 324-337.

Schenker, J.G., 2005. Assisted reproductive practice: religious perspectives. Reprod. Biomed. Online 10 (3), 310-319.

Segal, L., 2013. Out of Time: the Pleasures and the Perils of Ageing. Verso, London.

Spar, D., 2006. The Baby Business: How Money, Science and Politics Drive the Commerce of Conception. Harvard Business School Press, Boston, MA.
Stanworth, M., 1987. In: Reproductive Technologies: Gender, Motherhood, and Medicine. Polity Press, Cambridge.

Stoop, D., Cobo, A., Silber, S., 2014. Fertility preservation for age-related fertility decline. Lancet 384, 1311-1319.

Streeck, W., 2009. Flexible Employment, Flexible Families, and the Socialization of Reproduction. Max Planck Institute for the Study of Societies Working Paper Series, Cologne.

Terry, J., 1989. The body invaded: medical surveillance of women as reproducers. Social. Rev. 19, 13-43.

Thompson, C., 2005. Making Parents: the Ontological Choreography of Reproductive Technologies. MIT Press, Cambridge, MA.

TURKSTAT (Turkish Statistical Institute), 2016. Labor Force Statistics. Available at http://www.turkstat.gov.tr/, Accessed date: 15 December 2016.

Waldby, C., 2015a. 'Banking time': egg freezing and the negotiation of future fertility. Cult. Health Sex. 17, 470-482.

Waldby, C., 2015b. The oocyte market and social egg freezing: from scarcity to singularity. J. Cultural Economy 8, 275-291.

Van de Wiel, L., 2014. For whom the clock ticks: reproductive ageing and egg freezing in Dutch and British news media. Studies Mater. 6, 1-28.

World Bank, 2017. Education Statistics. Available at. http://databank.worldbank.org, Accessed date: 2 May 2017.

WVS (World Values Survey), 2014. Wave 6, 2010-2014. Official Aggregate v.20150418. World Values Survey Association. Available at. http://www.worldvaluessurvey.org/, Accessed date: 20 December 2016.

Zelizer, V.A., 1978. Human values and the market: the case of life insurance and death in 19th-century America. Am. J. Sociol. 84, 591-610.

Zola, I.K., 1972. Medicine as an institution of social control. Socio. Rev. 20 4, 487-504. 